\title{
Hospitalization and Post-hospitalization Outcomes Among Teaching Internal Medicine, Employed Hospitalist, and Locum Tenens Hospitalist Services in a Tertiary Center: a Prospective Cohort Study
}

\author{
Moaath K. Mustafa Ali, MD, MPH ${ }^{1,2}$ (1) Marwa M. Sabha, MD³, Sarah K. Mustafa, MD ${ }^{3}$, \\ Momen Banifadel, MD, MPH ${ }^{3}$, Sami Ghazaleh, $\mathrm{MD}^{3}$, Kanana M Aburayyan, $\mathrm{MD}^{3}$, \\ Marcel T. Ghanim, MD, MPH ${ }^{3}$, Mohammed T. Awad, MD ${ }^{3}$, Damynus N. Gekonde, MD”, \\ Amala R. Ambati, MD, MPH ${ }^{3}$, Ahmad Ramahi, MD MPH ${ }^{3}$, Ahmed M. Elzanaty, $\mathrm{MD}^{3}$, \\ Zeid Nesheiwat, DO ${ }^{3}$, Pinang $M$ Shastri, DO ${ }^{3}$, Mohammad Al-Sarie, MD ${ }^{3}$, and \\ John McGready, $P H D^{4}$
}

'Department of Medicine, University of Toledo/Promedica Toledo Hospital, Toledo, OH, USA; ${ }^{2}$ Bloomberg School of Public Health, Johns Hopkins University, Baltimore, MD, USA; ${ }^{3}$ Department of Medicine, University of Toledo, Toledo, OH, USA; ${ }^{4}$ Department of Biostatistics, Bloomberg School of Public Health, Johns Hopkins University, Baltimore, MD, USA.

BACKGROUND: There are no prospective studies comparing hospitalization and post-hospitalization outcomes between teaching internal medicine services and nonteaching hospitalists, and no prospective studies comparing these outcomes between locum and employed hospitalists.

OBJECTIVE: To compare the length of stay, hospital costs readmission rate, and mortality rate in patients treated by teaching internal medicine services vs. hospitalists and among patients treated by locum vs. employed hospitalists.

DESIGN: Prospective cohort study. Propensity score was used to obtain weighted estimates.

SETTING: Referral center.

PATIENTS: All patients 18 years and older admitted to internal medicine services.

INTERVENTION: Treatment by teaching internal medicine services vs. hospitalists. Treatment by locum hospitalists vs. employed hospitalists.

MAIN MEASURES: Primary outcome was adjusted length of stay and secondary outcomes included hospital cost, inpatient mortality, 30-day all-cause readmission, and 30-day mortality.

KEY RESULTS: A total of 1273 patients were admitted in the study period. The mean patient age was $61 \pm 19$ years, and the sample was $52 \%$ females. Teaching internal medicine physicians admitted 526 patients and non-teaching hospitalists admitted 747 patients. Being seen exclusively by teaching internal medicine physicians comports with a shorter adjusted hospital stay by 0.6 days (95\% CI -1.07 to $-0.22, P=.003$ ) compared to non-teaching hospitalists. Adjusted length of stay was 1 day shorter in patients seen exclusively by locums compared to patients seen exclusively by employed services $(95 \%$ CI -1.6 to $0.43, P<.001$ ) with an adjusted average hospital cost

Prior Presentations None

Received August 24, 2020

Accepted December 29, 2020

Published online January 25, 2021 saving of 1339 dollars (95\% CI -2037 to $-642, P<$ $.001)$. There was no statistically significant difference in other outcomes.

CONCLUSIONS: Teaching internal medicine services care was associated with a shorter stay but not with increased costs, readmission, or mortality compared to nonteaching services. In contrary to the "expected," patients treated by locums had shorter stays and decreased hospital costs but no increase in readmissions or mortality.

KEY WORDS: hospitalist; locum; teaching internal medicine; length of stay; patient readmission; hospital costs; mortality.

J Gen Intern Med 36(10):3040-51 DOI: $10.1007 / \mathrm{s} 11606-020-06578-4$

(C) Society of General Internal Medicine 2021

\section{INTRODUCTION}

After the "birth" of the hospitalist position in the mid-nineteen-nineties, the number of hospitalists has grown to fifty thousand physicians in 20 years. ${ }^{1}$ Nowadays, hospitalists are the most abundant internal medicine (IM) sub-specialty in the USA, with three-quarters of hospitals utilizing their services for inpatient care. ${ }^{1}$ In the USA, IM services are covered by different models, including teaching and non-teaching services. Non-teaching services are attended by hospitalists or outpatient-practicing internists. Many studies have compared these teaching services to the non-teaching services, which are routinely attended by internists who work in both inpatient and outpatient settings. ${ }^{2-4}$ In a metanalysis, there was no difference in length of stay (LOS), inpatient mortality, or 30-day readmission seen between teaching and non-teaching general internists services. ${ }^{4}$ Several retrospective studies have investigated the outcomes of care provided by teaching services compared to hospitalist services. ${ }^{5-8}$ These studies did not 
investigate readmission to other hospitals. Moreover, previous studies analyzed readmission and mortality, which are time-toevent variables, using logistic regression rather than survival analysis. There are no prospective studies comparing teaching IM services with non-teaching hospitalists.

Locum tenens in Latin means "temporarily taking the place of another". ${ }^{9}$ Locum physicians are used for shortterm coverage or when hospitals face difficulties in fulltime physician recruitment. ${ }^{10}$ Due to increasing and unmet medical needs worldwide, the utilization of locum physicians is increasing. ${ }^{1-16}$ During the COVID-19 pandemic, there is a rising demand for locum physician needs in the USA, especially in short-staffed hospitals. ${ }^{17,}{ }^{18}$ In the 2020 Survey of Temporary Physician Staffing Trends in the USA, around $85 \%$ of health care facility managers used locum physicians in the previous 12 months, and one-quarter used locum hospitalists in the previous 12 months, making hospitalists the second most common service in demand for locum physicians. ${ }^{16}$ Eighty-nine percent of managers thought the cost was a significant drawback of using locum physicians, and almost half of the managers considered unfamiliarity with department and practice as another drawback. Moreover, many believe that locum physicians provide lower patient safety and quality of care. ${ }^{10,19}$ However, there are few retrospective studies and no prospective studies investigating care provided by locum physicians in different medical specialties. ${ }^{19-21}$ Blumenthal et al. found that Medicare fee-for-service beneficiaries treated by locum physicians in plurality had similar mortality, higher hospital cost (HC), longer stay, and lower 30-day readmission compared to non-locum internist. ${ }^{21}$

In this prospective cohort study, we compare LOS, cost of hospitalization, inpatient mortality, 30-day all-cause readmission, and 30-day mortality in hospitalized patients treated by teaching IM vs. non-teaching hospitalist services at a single institution. We also compare the same outcomes between patients treated by locum hospitalists and employed (nonlocum) hospitalists.

\section{METHODS}

\section{Study Design}

The study protocol and consent forms were approved by Promedica Toledo Hospital and the University of Toledo institutional review boards (IRBs). We conducted a classical prospective cohort study with pre-specified intervals for data collection and follow-up using standardized protocols. Patients were recruited and consented between 2/25/2019 and 4/30/2019. After recruitment concluded, an IRB-approved amendment to protocol expanded the study sample to include patients who were missed and not consented during the recruitment window. The amendment complied with "common rule" regulations. ${ }^{22}$

\section{Study Site}

This study was conducted in Promedica Toledo hospital, an 800-bed tertiary center located in Toledo, Ohio. Promedica Health System includes 13 hospitals and serves Northwest Ohio and Southeast Michigan.

\section{Interventions}

Internal medicine services are divided into teaching services and non-teaching services. At the time of admission, patients are screened and assigned to either service type by a boardcertified physician. Admission assignments are rotated between teams and depend on the team's daily census. Teaching services have a cap of 20 patients per team, unlike hospitalists who lack a cap. The admitting teaching service had a cap of 12 new admissions every $24 \mathrm{~h}$, unlike non-teaching services, where no gap existed. Teaching services are staffed by 19 physicians. Non-teaching services are covered by 22 hospitalemployed physicians or 24 locum tenens physicians. Locum hospitalists and employed hospitalists could cover any of the non-teaching teams non-preferentially. There was no midlevel support provided in non-teaching services. Further details about intervention are described in a supplementary file.

\section{Participants}

The cohort study used dynamic recruitment, and the study population included all consecutive adult patients 18 years and older admitted for any medical reason to IM services at Promedica Toledo Hospital during the recruitment period. Patients were excluded if they refused to join the study, retracted their consent post recruitment, or were transferred to another non-IM service during hospitalization. Patients transferred to the intensive care unit after admission to the IM department were not excluded. Patients who were missed at the recruitment period were included, and their data were collected retrospectively.

\section{Screening and Consenting Protocol}

Every $12 \mathrm{~h}$, all patients admitted to IM services were screened for eligibility and assigned to physicians to obtain consents, baseline characteristics, and contact information of patients and family members for outcomes ascertainment post-discharge. A team of 10 physicians contributed to consenting over 65 consecutive days, and at least three physicians obtained consents daily.

\section{Variables}

Data extracted by physicians included demographics, food security (yes/no), residence before admission, insurance type, principal admission diagnosis, and comorbidities. The primary exposures in this study were the types of admitting physicians: teaching IM services, employed hospitalist services, or locum hospitalist services. Further details about the methodology used to collect variables and exposure are described in a supplementary file. 


\section{Study Outcomes}

The primary outcome of the study was the LOS. The secondary outcomes of the study were HC, inpatient mortality, 30day readmission, and 30-day mortality. Hospitalization outcomes included LOS, HC, and inpatient mortality. Length of stay was measured in integer days. A stay length of 1 day was defined as being admitted to IM services for any duration of a calendar day between 12:00 a.m. and 11:59 p.m. Hospital costs included the sum of variable direct and fixed direct costs. Senior analysts in Promedica's financial department provided hospital cost outcomes for analysis. Further details regarding $\mathrm{HC}$ are described in supplementary. Inpatient mortality (yes/ no) was recorded as a "yes" if the patient died during their index hospitalization.

Post-hospitalization outcomes included the 30-day all-cause mortality rate and the 30-day all-cause readmission rate. Allcause readmission included any admission for any medical reason to any hospital, excluding elective non-urgent admissions (i.e., elective surgery) and admissions to psychiatry hospitals. Both observation and inpatient status were counted as admissions.

Both active and passive ascertainment captured 30-day mortality and readmission outcomes. A group of 4 physicians contacted all enrolled patients on or shortly after 31-days postdischarge, and inquired about readmission within the 30 days post-discharge. Patients who did not answer were contacted through other methods, including email, text messages, voice messages, or via proxy through family members or other contacts based on patient preference. In these situations where the patient was not reached directly by phone, at least two additional separate attempts to contact the patient, family members, or friends for outcome ascertainment per patient preference.

Passive ascertainment was determined by checking Promedica electronic health records and the University of Toledo health medical records for readmission or mortality. Health records were checked at least 3 months post-discharge to maximize data accuracy. For patients with whom an investigator failed to contact post-discharge, surrogates were used to assess vitality. Surrogates included clinic visits, emergency visits, or laboratory checks at any period after discharge.

Patients were determined to have survived 30 days or more post-discharge if they were contacted successfully, or a surrogate was used as evidence of vitality. Readmission events and dates were determined if the patient reported readmission or readmission was evident in checking electronic medical records. Readmission and mortality for patients who were missed during consenting were determined passively.

Data Sources. Physicians collected data from collection sheets used at the screening process, Promedica and University of Toledo electronic health records, communication with patient/ family members, and Epic's Care Everywhere health network. All outcomes were collected or calculated electronically to maximize accuracy. After compiling all data, it was checked extensively for accuracy.

Promedica Health System utilizes Epic software, which supports a health network connecting all hospitals that utilize Epic; this feature is called Care Everywhere ${ }^{\circledR}$. Data was also mounted from Care Everywhere to cover a large geographical area, including most referral hospitals in Northwest Ohio and Southeast Michigan. Referral health systems that use Care Everywhere include Mercy Health, Cleveland Clinic, Ohio State University Medical Center, Henry Ford Health System, University of Michigan, and Beaumont Health System. ${ }^{23}$ Lucas County, including Toledo city, is served by three separate hospital systems: Promedica Health Care, Mercy Health, and University of Toledo Medical Center. ${ }^{24}$

\section{STATISTICAL ANALYSIS}

In this paper, two major comparisons are considered: teaching IM services vs. non-teaching services and employed vs. locum hospitalist services. The first comparison was made using all patients in the original study sample. For the second comparison, the study sample included patients who were seen either by employed hospitalists exclusively or locum hospitalists exclusively throughout their index hospitalizations. A secondary analysis was performed based on all patients admitted to non-teaching services using the percentage of inpatient days the patient was treated by locum physicians as the exposure.

Descriptive statistics are presented as means with standard deviation for continuous variables and percentages for categorical variables and are presented separately for the exposed and unexposed groups in each of the two primary comparisons. Baseline characteristics were compared using a $t$ test for continuous variables and Pearson's chi-square or Fisher's exact test for categorical variables. Survival data were compared using a log-rank or Gehan-Breslow-Wilcoxon rank test.

Multiple regressions with inverse propensity score weighting were used to compare outcomes between teaching and nonteaching services, and employed and locum services, to determine adjusted average treatment effects. Multivariable linear regression models using log-transformed $\mathrm{HC}$ were calculated to account for potential non-linearity and as a sensitivity analysis check.

Regression diagnostics were used to evaluate model assumptions, including the linearity of the outcome/locum percentage association in the third set of models. All statistical tests were two-sided. Tests with $P$ value $<0.05$ were considered statistically significant. Investigators used $\mathrm{R}$ statistical software (version 3.6.1) for analysis. ${ }^{25}$

\section{Propensity score}

Propensity scores for being cared for by teaching service or locum were calculated using logistic regression. Both inverse probability weighting and weighting by the odds were used to 
calculate regression models. Further details regarding propensity score calculation, matching method, methods used to manage missing data, and sample size calculations are described in a supplementary file.

\section{RESULTS}

\section{Study Population Characteristics}

During the study period, 1123 unique patients were admitted at least once to IM services and agreed to join the study. These resulted in a total of 1273 separate admissions analyzed (Fig. 1). Around $5 \%$ of patients $(n=63)$ refused to join the study. Around $3 \%$ of patients $(n=41)$ were missed at initial screening, and their data were collected retrospectively. This led to missing data regarding food security, assistance at home, and residence before admission. Teaching and non-teaching services' daily census was not different (16.2 vs. 15.5 patients, $P=.7$ ).

Table 1 shows unadjusted and adjusted baseline characteristics of the teaching vs. non-teaching services $(n=1273$ patients) and locum physicians vs. employed physicians ( $n=$ 747) using propensity score weighting. In the complete cohort, the mean age was $61 \pm 19$ years with a range of 18-97 years; the female percentage was 52\%. Appendix Figures 2-4 demonstrate covariate balance before and after propensity weighting for different comparisons. Details regarding treating physician characteristics are described in the appendix.

\section{Patient Outcomes}

Using descriptive statistics, the propensity score-adjusted LOS was 0.65 days shorter in teaching IM $(5.2 \pm 0.17)$ compared to non-teaching services $(5.8 \pm 0.17)(P=.01)$. The propensity score-adjusted average $\mathrm{HC}$ was not statistically significantly different between teaching $(6108 \pm 357$ dollars $)$ and nonteaching services $(5987 \pm 204$ dollars $)(P=.77)$. The adjusted median HC was 4056 dollars in teaching services compared to 4382 dollars in non-teaching $(P=.13)$.

In supplementary file, Appendix Tables 1-13 show the results from weight-adjusted multiple regression models for the LOS, HC, inpatient mortality, 30-day all-cause readmission, and 30-day all-cause mortality outcomes of different comparisons.

Using weighted-multivariable analysis, patients treated by teaching services had 0.6 days shorter adjusted average LOS $(-0.65,95 \% \mathrm{CI}-1.07$ to $-0.22, P=.003)$ and a higher average adjusted $\mathrm{HC}$ of 166 dollars $(166,95 \% \mathrm{CI}-547$ to $880, P=.64$ ) but statistically insignificant. Both services had a similar adjusted inpatient mortality (odds ratio $=1.04,95 \% \mathrm{CI}$ 0.38 to $2.84, P=.93$ ). There were no qualitative or statistically significant differences in 30-day readmissions $(\mathrm{HR}=0.97$, 95\% CI 0.72 to $1.3, P=.85$ ). Patients treated by teaching services had 20\% higher 30-day mortality, but this difference was not statistically significant $(\mathrm{HR}=1.26,95 \%$ CI 0.66 to $2.38, P=.47)$. On weighted-multivariable regression for logtransformed $\mathrm{HC}$, teaching services care resulted in a $4 \%$ lower cost compared to non-teaching services (95\% CI $-12 \%$ to $3.7 \%, P=.3)$. Figures 2 and 3 show 30 -day readmission and 30-day mortality survival curves derived from Cox proportional hazards models in teaching and non-teaching services comparison.

In the locum vs. employed comparison, we estimated outcomes by two methods. In the first method, we compared patients who were seen exclusively by locum vs. patients seen exclusively by employed hospitalists, we used propensity score weighting and obtained average treatment of the treated estimand. Using descriptive statistics, the average length of stay was 1.2 days shorter in patients treated by locum physicians $(3.45 \pm 1.7)$ compared to employed hospitalists (4.92 \pm $2.7)$ on $t$ test $(P=.003)$. The average HC was lower by 1765 dollars in locum hospitalists $(3358 \pm 2627)$ compared to employed hospitalists $(5123 \pm 3950)$ on $t$ test $(P<.001)$. The median HC was 2332 dollars in locum hospitalists and 3387 dollars in employed hospitalists $(P<.005)$. Using weighted-multivariable regression, patients treated by locum physicians had an adjusted hospital stay 1 day shorter on average compared to patients treated by employed hospitalists $(-1,95 \% \mathrm{CI}-1.6$ to $-0.43, P<.001)$. The adjusted $\mathrm{HC}$ on average for patients treated by locum physicians was lower by 1339 dollars (95\% CI -2037 to $-642, P<.001)$. On

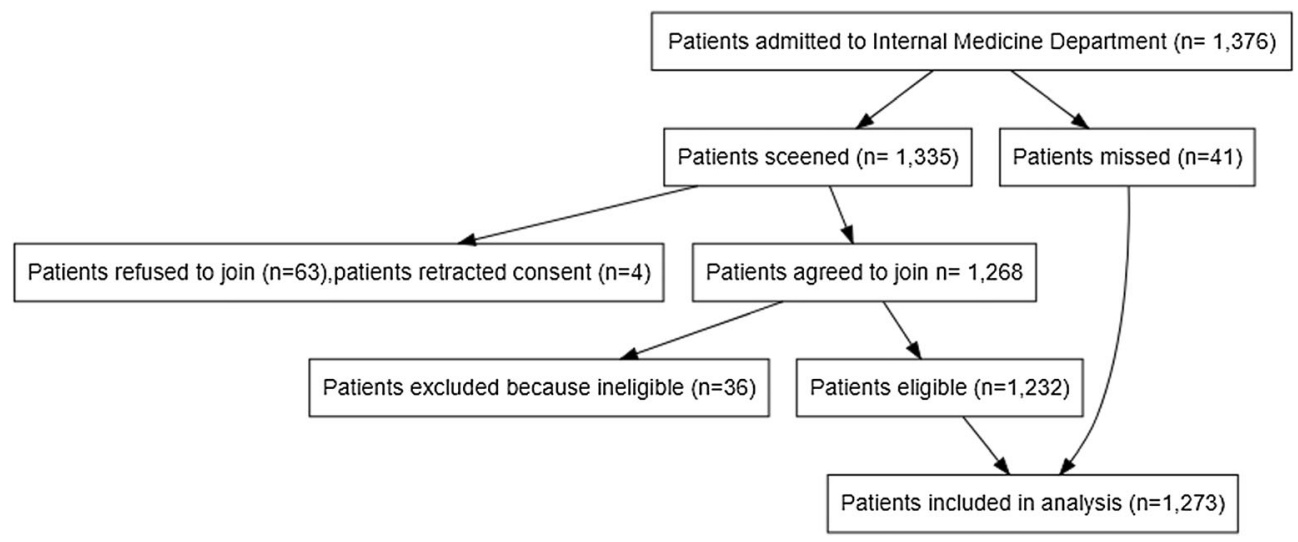

Figure 1 Flow chart of the study population. 


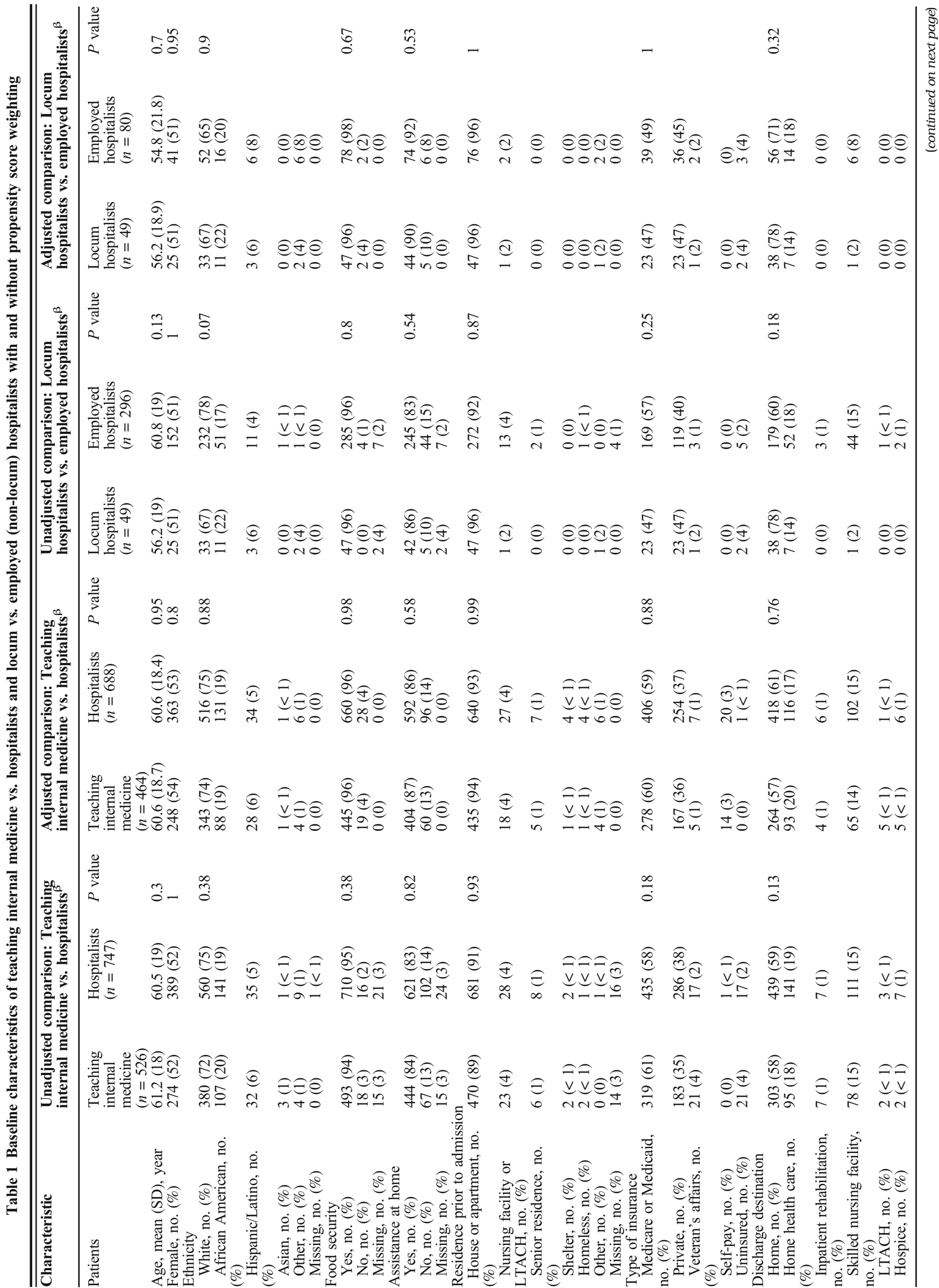




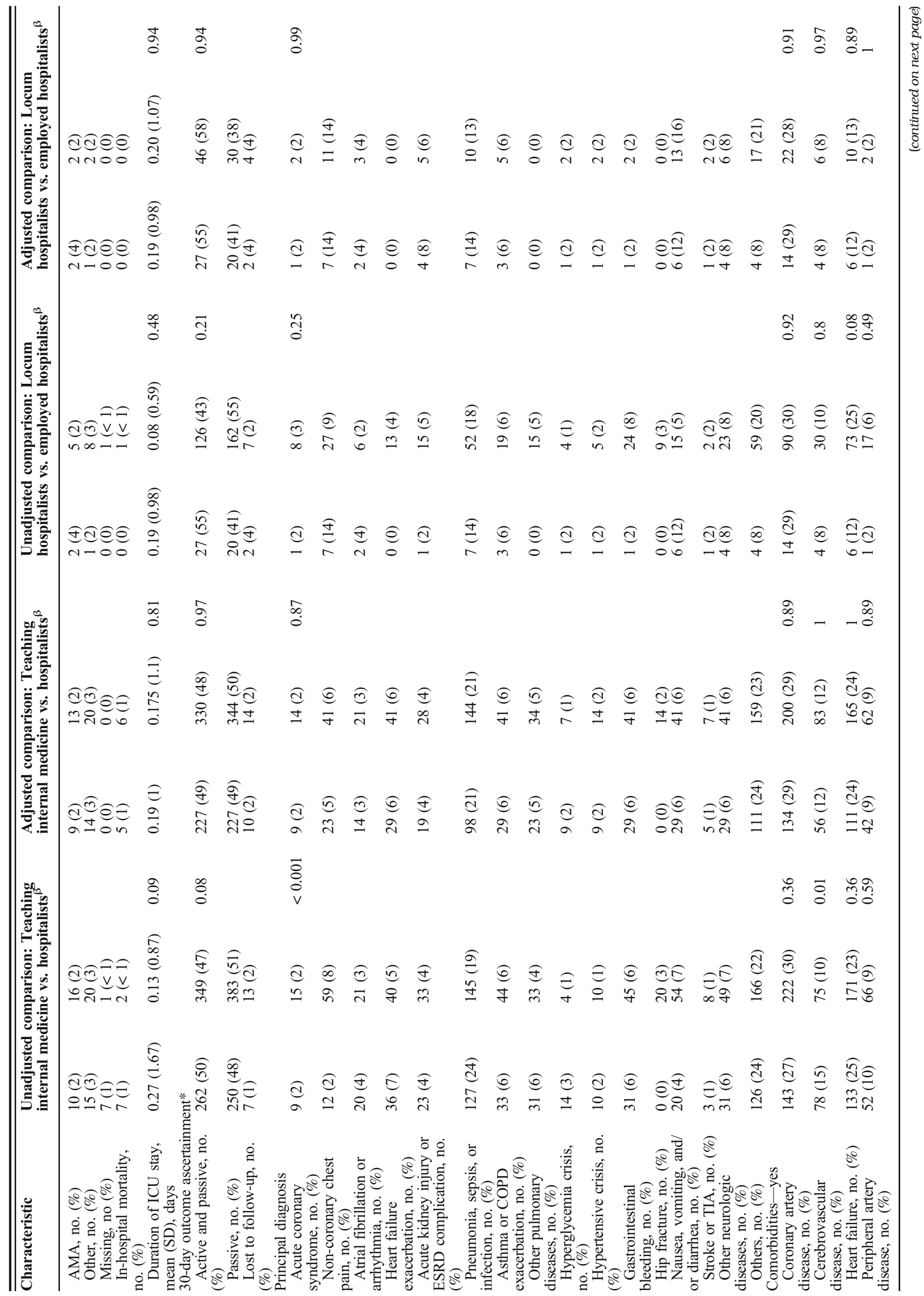




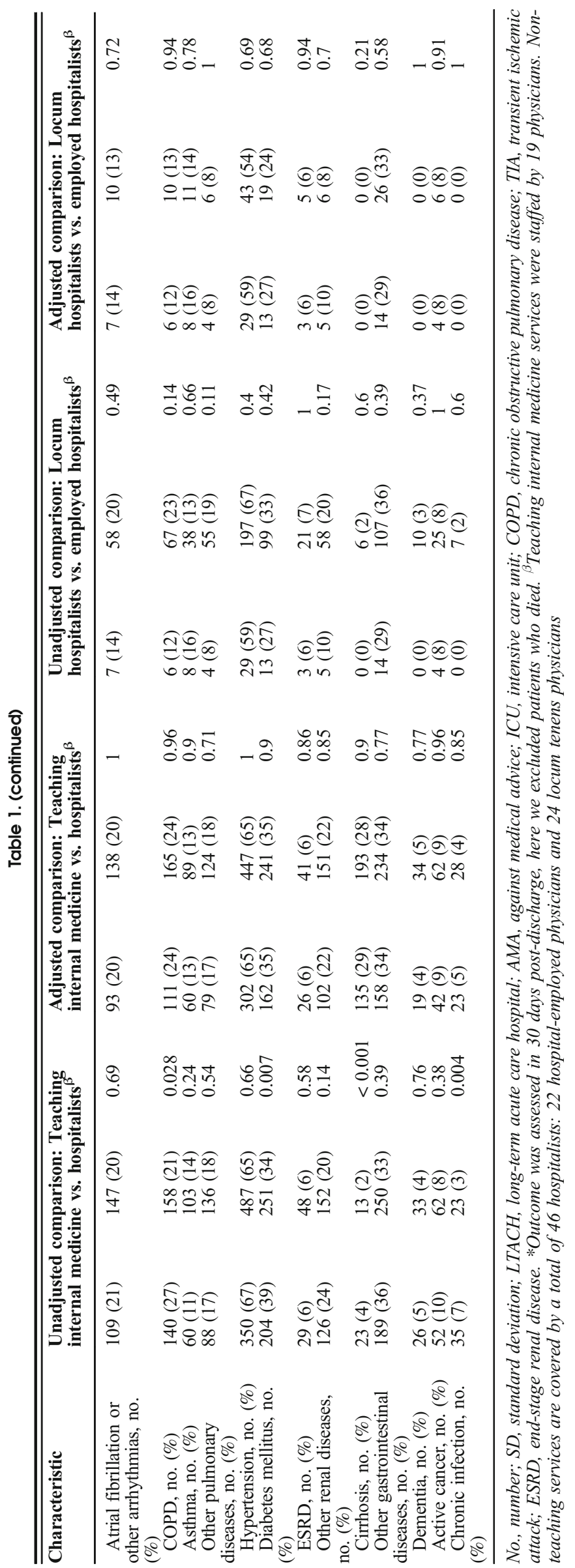




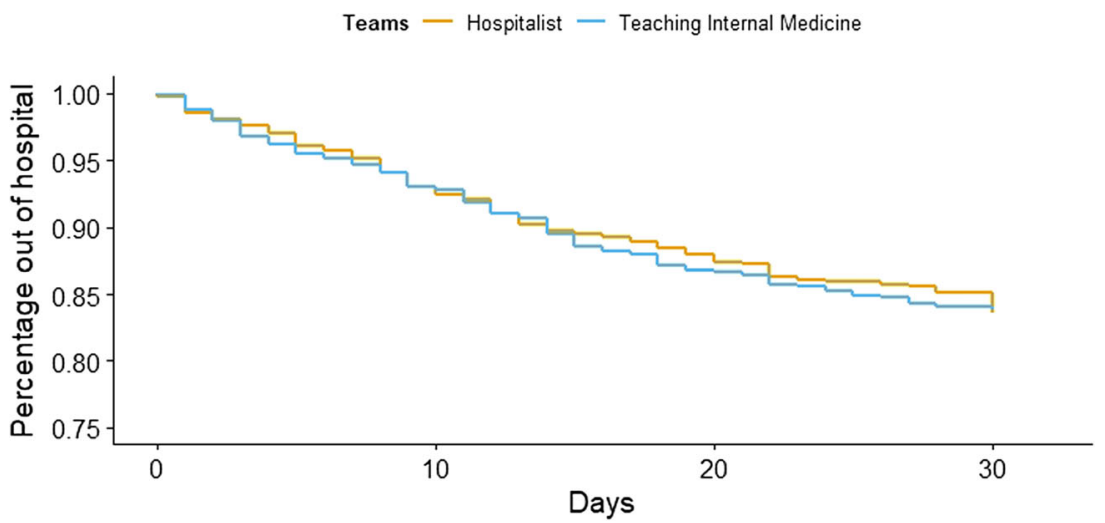

Figure 2 Thirty-day all-cause readmission in teaching internal medicine services and hospitalist services using weight-adjusted Cox proportional hazards survival curve estimates.

weighted-multivariable regression for log-transformed $\mathrm{HC}$, locum physician care resulted in a $23 \%$ lower cost compared to employed hospitalists $(95 \% \mathrm{CI}-40 \%$ to $-7 \%, P=.005)$.

There was no difference in 30-day mortality based on a propensity score weight-adjusted Wilcoxon rank test $(P=.62)$. The Cox proportional hazards regression-based comparison for mortality was not calculable because there were no deaths in patients treated by either group. Based on the propensity score, weight-adjusted multivariable Cox proportional hazards regression, no difference was found in readmission rates (HR $=1.6,95 \%$ CI 0.6 to $4.24, P=.34$ ). Appendix Figure 5 shows 30-day readmission survival curves derived from Cox proportional hazards models in the above comparison.

In the secondary analysis of the outcome to locum-exposure associations, we obtained the average treatment effect estimand. The adjusted mean difference in hospital stays decreased by 0.09 days $(95 \% \mathrm{CI}-0.01$ to $-0.17, P=.01)$ for every $10 \%$ increment in locum percentage supervision of patients' hospitalization. Similarly, the adjusted mean difference of $\mathrm{HC}$ decreased by 84 dollars $(95 \% \mathrm{CI}-171$ to $2.6, P=$ .057 ) for every $10 \%$ increase in locum supervision of patient hospitalization, but this was not statistically significant. Using log-transformed $\mathrm{HC}$ as the dependent variable, an increase in locum care from 0 to $100 \%$ was associated with an $18 \%$ drop in $\mathrm{HC}(95 \% \mathrm{CI}-33 \%$ to $-3 \%, P=.018)$. Increasing exposure to locum physicians during hospitalization was not significantly associated with increased adjusted-risk for 30-day readmission or mortality $(\mathrm{HR}=1.6,95 \% \mathrm{CI} 0.81$ to $2.97, P=.18)(\mathrm{HR}$ $=0.47,95 \%$ CI 0.09 to $2.4, P=.37$ ). Incremental supervision of patient hospitalization by locum physicians did not impact inpatient mortality (odds ratio $=0.38,95 \%$ CI $0.0004-320, P$ $=.78)$.

\section{DISCUSSION}

In this study, we compare the outcomes of patients treated by different services: teaching IM services, non-teaching hospitalists, and locum hospitalists using a prospective design.

Table 2 summarizes studies comparing teaching IM service with non-teaching hospitalists; teaching IM services do not protract LOS in hospitalized patients. ${ }^{5-8}$ Consistent with our study findings, the hospital stay is shorter by approximately half a day in these studies. ${ }^{5-8}$ The shorter hospital stays resulted in lower $\mathrm{HC}$ in many of these studies. However, there was no cost-saving at our institution using descriptive statistics or regression-derived estimates. Different theories could explain this: increased spending of teaching teams per day of hospitalization, no actual difference in $\mathrm{HC}$, or insufficient power of our study to detect a difference. In our study, the

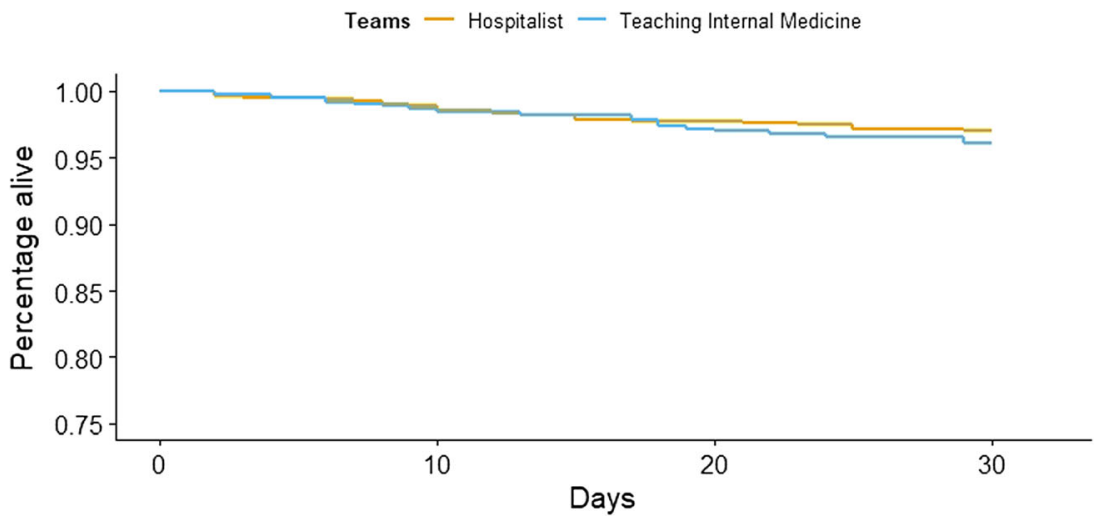

Figure 3 Thirty-day all-cause mortality in teaching internal medicine services and hospitalist services using weight-adjusted Cox proportional hazards survival curve estimates. 
Table 2 Studies comparing teaching internal medicine vs. hospitalists and locum vs. employed (non-locum) internal medicine physicians

\begin{tabular}{|c|c|c|c|c|c|c|}
\hline$\overline{\text { Author/year }}$ & Design/setting & $\begin{array}{l}\text { Study population/ } \\
\text { allocation }\end{array}$ & Comparison & Outcomes & Pertinent findings* & Remarks \\
\hline \multicolumn{7}{|c|}{ Teaching internal medicine services vs. hospitalists } \\
\hline $\begin{array}{l}\text { Current } \\
\text { study/2020 }\end{array}$ & $\begin{array}{l}\text { Prospective } \\
\text { cohort study/ } \\
\text { single institu- } \\
\text { tion. }\end{array}$ & $\begin{array}{l}\text { All comers } \geq 18 \\
\text { years/admissions ro- } \\
\text { tated between teams } \\
\text { and depend on team } \\
\text { census. }\end{array}$ & $\begin{array}{l}\text { Teaching IM } \\
\text { services: non- } \\
\text { teaching hospital- } \\
\text { ist services. }\end{array}$ & $\begin{array}{l}\text { Propensity } \\
\text { adjusted LOS, } \\
\text { HC, inpatient } \\
\text { mortality, } 30 \text {-day } \\
\text { all-cause read- } \\
\text { mission rate, and } \\
\text { 30-day mortality } \\
\text { rate. }\end{array}$ & $\begin{array}{l}\text { ATE estimates: } \\
\text { LOS 0.6 days } \\
\text { shorter in teaching } \\
\text { compared to } \\
\text { hospitalists. No } \\
\text { difference in HC, } \\
\text { inpatient mortality } \\
\text { odds ratio, } \\
\text { readmission, or } 30- \\
\text { day-mortality. }\end{array}$ & $\begin{array}{l}\text { Baseline } \\
\text { characteristics and } \\
\text { observable } \\
\text { confounders were } \\
\text { controlled using } \\
\text { propensity score and } \\
\text { multiple regression. } \\
\text { Readmission was } \\
\text { defined as } \\
\text { readmissions to any } \\
\text { hospital. }\end{array}$ \\
\hline Perez $^{6} / 2018$ & $\begin{array}{l}\text { Retrospective } \\
\text { cohort study/ } \\
\text { single institu- } \\
\text { tion. }\end{array}$ & $\begin{array}{l}\text { Patients with no } \\
\text { identifiable } \\
\text { attending physician/ } \\
\text { admissions are ro- } \\
\text { tated between the } 2 \\
\text { teams. Hospital } \\
\text { transfers admitted } \\
\text { exclusively to teach- } \\
\text { ing service. }\end{array}$ & $\begin{array}{l}\text { Teaching } \\
\text { hospitalists: non- } \\
\text { teaching } \\
\text { hospitalists. }\end{array}$ & $\begin{array}{l}\text { Propensity } \\
\text { adjusted LOS, } \\
\text { HC, in-hospital } \\
\text { mortality, and } \\
\text { 30-day readmis- } \\
\text { sion odds ratio. }\end{array}$ & $\begin{array}{l}\text { LOC } \sim 0.5 \text { days } \\
\text { shorter in teaching } \\
\text { hospitalists. HC } \\
\text { was } 333 \text { dollars } \\
\text { lower in teaching } \\
\text { hospitalists. Same } \\
\text { mortality and } 30- \\
\text { day readmission. }\end{array}$ & $\begin{array}{l}\text { The study sample } \\
\text { included patients } \\
\text { admitted for the top } \\
20 \text { Medicare Severity } \\
\text { DRG. Patients } \\
\text { admitted to the } \\
\text { intensive unit were } \\
\text { excluded. } \\
\text { Readmission is } \\
\text { defined as } \\
\text { readmissions to the } \\
\text { same hospital. Non- } \\
\text { teaching services } \\
\text { could have midlevel } \\
\text { providers. }\end{array}$ \\
\hline $\begin{array}{l}\text { Abusaada }^{7} / \\
2017\end{array}$ & $\begin{array}{l}\text { Retrospective } \\
\text { cohort study/ } \\
\text { single institu- } \\
\text { tion. }\end{array}$ & $\begin{array}{l}\text { Patients admitted } \\
\text { with COPD } \\
\text { exacerbation/ } \\
\text { allocation is from } \\
\text { different source } \\
\text { populations and is } \\
\text { time variable. }\end{array}$ & $\begin{array}{l}\text { Academic IM: } \\
\text { hospitalist. }\end{array}$ & $\begin{array}{l}\text { LOS, HC, } \\
\text { inpatient } \\
\text { mortality, and } \\
\text { 30-day all-cause } \\
\text { readmission odds } \\
\text { ratio. }\end{array}$ & $\begin{array}{l}\text { LOC } \sim 0.8 \text { days } \\
\text { shorter in teaching } \\
\text { IM. HC in teaching } \\
\text { was } 0.6 \text { times that } \\
\text { in hospitalist. Same } \\
\text { mortality and } 30- \\
\text { day readmission. }\end{array}$ & $\begin{array}{l}\text { Readmission is } \\
\text { defined as } \\
\text { readmissions to the } \\
\text { same hospital. }\end{array}$ \\
\hline $\mathrm{Chin}^{5} / 2014$ & $\begin{array}{l}\text { Retrospective } \\
\text { cohort study/ } \\
\text { single institu- } \\
\text { tion. }\end{array}$ & $\begin{array}{l}\text { All comers/ } \\
\text { allocation not clear. }\end{array}$ & $\begin{array}{l}\text { Academician } \\
\text { preceptor IM: } \\
\text { hospitalist } \\
\text { preceptor IM: } \\
\text { non-teaching hos- } \\
\text { pitalist. }\end{array}$ & $\begin{array}{l}\text { LOS, HC, and } \\
\text { 30-day readmis- } \\
\text { sion odds ratio. }\end{array}$ & $\begin{array}{l}\text { Both hospitalist- } \\
\text { preceptors and } \\
\text { academician- } \\
\text { preceptors were as- } \\
\text { sociated with } \\
\text { shorter LOS } \sim 0.3 \\
\text { days and less HC, } \\
\text { but readmissions } \\
\text { were } 1.2 \text { higher } \\
\text { compared to non- } \\
\text { teaching } \\
\text { hospitalists. }\end{array}$ & $\begin{array}{l}\text { Excluded patients who } \\
\text { left against medical } \\
\text { advice, patients who } \\
\text { died, and patients } \\
\text { whose hospitalization } \\
\text { was protracted for } \\
\text { "social reasons." }\end{array}$ \\
\hline $\begin{array}{l}\text { Everett, } \\
2007\end{array}$ & $\begin{array}{l}\text { Retrospective } \\
\text { cohort study/ } \\
\text { single institu- } \\
\text { tion. }\end{array}$ & $\begin{array}{l}\text { All comers/ } \\
\text { allocation varies } \\
\text { based on source } \\
\text { populations (referral } \\
\text { source) and varies } \\
\text { with time of the day. }\end{array}$ & $\begin{array}{l}\text { Academic IM: } \\
\text { hospitalist: } \\
\text { community } \\
\text { internist. }\end{array}$ & $\begin{array}{l}\text { LOS, HC, } \\
\text { inpatient } \\
\text { mortality, and } \\
\text { 30-day readmis- } \\
\text { sion odds ratio. }\end{array}$ & $\begin{array}{l}\text { Teaching IM had } \\
40 \% \text { shorter LOS } \\
\text { and } 30 \% \text { lower HC, } \\
\text { but readmissions } \\
\text { were } 1.25 \text { times } \\
\text { higher. No } \\
\text { difference in } \\
\text { mortality. }\end{array}$ & $\begin{array}{l}\text { Hospitalists treat } \\
\text { patients of community } \\
\text { physicians outside the } \\
\text { hospital system. } \\
\text { Hospitalist had } \\
\text { midlevel providers. } \\
\text { Academic services } \\
\text { included IM and } \\
\text { medicine-pediatric } \\
\text { residents. Readmis- } \\
\text { sion is defined as } \\
\text { readmissions to same } \\
\text { hospital. }\end{array}$ \\
\hline \multicolumn{7}{|c|}{ Locum hospitalists vs. employed (non-locum) hospitalists } \\
\hline \multirow[t]{2}{*}{$\begin{array}{l}\text { Current } \\
\text { study/2020 }\end{array}$} & $\begin{array}{l}\text { Prospective } \\
\text { cohort study/ } \\
\text { single institu- } \\
\text { tion. }\end{array}$ & $\begin{array}{l}\text { All comers } \geq 18 \\
\text { years/unpredictable } \\
\text { allocation. }\end{array}$ & $\begin{array}{l}\text { Locum } \\
\text { hospitalists: } \\
\text { employed } \\
\text { hospitalists. }\end{array}$ & $\begin{array}{l}\text { Propensity } \\
\text { adjusted LOS, } \\
\text { HC, inpatient } \\
\text { mortality, 30-day } \\
\text { readmission rate, } \\
\text { and } 30 \text {-day mor- } \\
\text { tality rate. }\end{array}$ & $\begin{array}{l}\text { ATT estimates: } \\
\text { LOS 1 day } \\
\text { shorter in LH, HC } \\
1382 \text { dollars lower } \\
\text { in LH. Same } \\
\text { readmission and } \\
\text { mortality. }\end{array}$ & $\begin{array}{l}\text { The analysis was done } \\
\text { for patients' entire } \\
\text { hospital stay and were } \\
\text { treated by LH or EH, } \\
\text { exclusively. }\end{array}$ \\
\hline & & & $\begin{array}{l}\text { Locum } \\
\text { percentage, } \\
\text { continuous } \\
\text { variable. }\end{array}$ & $\begin{array}{l}\text { Generalized } \\
\text { propensity } \\
\text { adjusted LOS, } \\
\text { HC, inpatient } \\
\text { mortality, } 30 \text {-day } \\
\text { readmission rate, }\end{array}$ & $\begin{array}{l}\text { ATE estimates: } \\
\text { LOS decreased } 0.09 \\
\text { days with every } \\
10 \% \text { increased care } \\
\text { by LH compared to } \\
\text { EH. No significant }\end{array}$ & $\begin{array}{l}\text { Locum percentage } \\
\text { calculated by dividing } \\
\text { days covered by LH } \\
\text { by the sum of LH and } \\
\text { EH. The analysis was } \\
\text { done to account for }\end{array}$ \\
\hline
\end{tabular}


Table 2. (continued)

\begin{tabular}{|c|c|c|c|c|c|c|}
\hline Author/year & Design/setting & $\begin{array}{l}\text { Study population/ } \\
\text { allocation }\end{array}$ & Comparison & Outcomes & Pertinent findings* & Remarks \\
\hline & & & & $\begin{array}{l}\text { and } 30 \text {-day mor- } \\
\text { tality rate. }\end{array}$ & $\begin{array}{l}\text { change in } \mathrm{HC} \text {, } \\
\text { readmission, or } \\
\text { mortality. }\end{array}$ & $\begin{array}{l}\text { inevitable cross-over } \\
\text { in patient care. }\end{array}$ \\
\hline $\begin{array}{l}\text { Blumenthal }{ }^{21} / \\
2017\end{array}$ & $\begin{array}{l}\text { Retrospective } \\
\text { cohort/data base } \\
\text { study of multi- } \\
\text { institution. }\end{array}$ & $\begin{array}{l}\text { A random sample of } \\
\text { Medicare } \\
\text { beneficiaries, } \\
\text { national data. } \\
\text { Patients } \geq 65 \text { years/ } \\
\text { allocation unclear. }\end{array}$ & $\begin{array}{l}\text { Locum: non- } \\
\text { locum IM physi- } \\
\text { cians. Locum } \\
\text { physicians not } \\
\text { necessarily IM. } \\
\text { Some cross over } \\
\text { permitted. }\end{array}$ & $\begin{array}{l}\text { LOS, HC, 30-day } \\
\text { readmission rate, } \\
\text { and } 30-\text { day mor- } \\
\text { tality rate }\end{array}$ & $\begin{array}{l}\text { LOS } \sim 0.4 \text { days } \\
\text { longer in locum } \\
\text { physicians, HC was } \\
124 \text { dollars more in } \\
\text { Locum hospitalists. } \\
\text { No difference in } \\
\text { mortality. 30-day } \\
\text { readmission was } \\
\text { less in LH (22.8\% } \\
\text { vs. } 23.83 \%) \text {. }\end{array}$ & $\begin{array}{l}\text { Locum and non- } \\
\text { locum are not neces- } \\
\text { sarily hospitalists. Lo- } \\
\text { cum physician } \\
\text { hospitalizations are } \\
\text { defined as those in } \\
\text { which locums provid- } \\
\text { ed plurality of care } \\
\text { and not totality. }\end{array}$ \\
\hline
\end{tabular}

IM, internal medicine; LOS, length of stay; HC, hospital cost; ATE, average treatment causal effect; DRG, diagnosis-related group; COPD, chronic obstructive pulmonary disease; ATT, average treatment on the treated causal effect. *Pertinent findings are statistically significant differences reported. Studies included that compare teaching services with hospitalists. Non-teaching general IM physicians who practice in the inpatient and outpatient settings were not included in the table. ${ }^{\beta}$ Thirty-day mortality reported in Blumenthal et al.'s study is mortality within 30 days of admission. In our study, mortality was assessed in 30 days after discharge. NB, readmission and mortality rates were assessed using a hazard ratio in this study

shortened hospitalization in teaching teams did not compromise patient safety; there was no increased inpatient mortality, 30-day readmission, or 30-day mortality. The authors postulate that the presence of more than one team member treating patients facilitates an earlier discharge when medically fit. In this study, we only analyzed the outcomes of patients admitted during the February-May period. Several studies showed that academic teams care may vary with trainee changeover in July. ${ }^{26}$ On the other hand, other studies showed no difference in outcomes during the July changeover. ${ }^{27-29}$ Studies described in Table 2 included patients admitted over protracted periods and had similar conclusions to our study.

Previous studies comparing these two services targeted different source populations and had variable allocation to comparatives arms, as demonstrated in Table 2. Innate to observational studies, the non-randomized allocation can lead to biased estimates. On the other hand, randomized clinical trials maximize the homogenous distribution of observed and unobserved confounders in the comparative arms. ${ }^{30}$ Commonly in teaching hospitals, patients with higher medical complexity and "medically-challenging" are assigned preferentially to teaching services. To address this potential unequal allocation, the authors used 16 different admissions diagnoses, 16 comorbidities, and nine other variables to obtain propensity scorebased estimates. All variables were well-balanced with standardized bias scores $<0.1$. Despite the potential "unequal" allocation, teaching services had a shorter hospital stay with no difference in other outcomes. Previous studies utilized retrospective design to compare both teams. In this study, we used a prospective design for the following reasons ${ }^{1}$ : to collect information about food security, presence of assistance at home, and the previous residence before admission which are not routinely collected at admission ${ }^{2}$; to obtain consent necessary to actively contact patients and their secondary contacts to obtain information about possible readmission to outside hospitals and possible death; and $^{3}$ to obtain consent to access patient's medical records in outside facilities. Our study is unique in that we had a high rate of locum hospitalist utilization during the recruitment period. To check if our study results were reproducible, we estimated outcomes using unweighted multivariable regression (results not shown), weighted descriptive statistics, and weighted multivariable regression; all of which showed similar estimates.

Despite the utilization of locum physicians is pervasive in the USA and the rest of the world, ${ }^{11-16}$ their outcomes are mostly unknown. ${ }^{19-21}$ Only one study has investigated locum physician outcomes in patients admitted to IM services (Table 2). ${ }^{21}$ The study sample included 38,475 Medicare admissions treated by locum physicians in plurality compared to $1,780,398$ admissions treated by IM physicians. The authors found that LOS was 0.4 days longer in locum physicians with no difference in mortality. The absolute risk of 30 -day readmission was $1 \%$ higher in employed physicians. Our study is different in some aspects: we compared locum hospitalists to employed hospitalists without including generalists. Most locum care was in small- to medium-sized rural and suburban hospitals in Blumenthal's study in comparison to our study, which was conducted in a tertiary hospital serving urban and suburban areas. Another difference is that we compared patients exclusively treated by either team with no overlap in care; this facilitates obtaining homogenous and precise results. Our analysis found that patients treated by locum physicians had shorter and less expensive hospitalization yet with no increased readmission or mortality. A reason that may explain these outcomes is that hospitals require locum physicians and agencies to maintain high professional standards, and this may lead to increased competition between locum physicians and agencies and hence the quality of care. This "competitive environment" may not necessarily exist in contracted physicians. Locum physicians were younger on average and were more recent 
graduates. The significance of the variability in age and number of years in practice between locum and employed hospitalists on outcomes was unclear.

\section{LIMITATIONS}

Because our study is observational, it has several limitations. Our study is subjected to confounding on observed and unobserved factors. To control for confounding via observed factors, we used propensity score weighting followed by regression to infer causal associations.

The study is based on patients seen in is a single medical center study, which may limit the generalizability of the results. A multi-institutional study, where a larger pool of physicians examined, would improve the generalizability of the study results. On the other hand, single-institution studies allow for a homogenous distribution of significant background covariates, including the same nursing floors, the same nursing staff, and the same period. Another limitation to the generalizability is that most of the patients admitted during our study period had food security and were admitted from home.

Around $50 \%$ of patients' readmission outcomes were determined using chart review because of the inability to contact patients. In patients who were contacted successfully, only two patients' readmission dates $(0.2 \%)$ were changed to an earlier time compared to chart-review-determined outcomes, indicating the high concordance between passive and active methods for outcome determination. This is likely because investigators used Promedica's medical record, University of Toledo's medical record, and Care Everywhere network to capture outcomes. Excluding psychiatry hospitals, Lucas County is served exclusively by 3 hospital systems: Promedica Health Care, Mercy Health, and University of Toledo, ${ }^{24}$ all of which medical records were searched. Mortality outcomes were accurately determined whether passive or active methods were used. Out of 1273 admissions, only 20 (1.5\%) patient 30-day outcomes could not be determined; those outcomes were right-censored. Lastly, our study was only powered to detect a difference in LOS.

\section{CONCLUSIONS}

Teaching IM services provided shorter hospital stay with no increased HC, inpatient mortality, 30-day all-cause readmission, or 30-day all-cause mortality compared to non-teaching services. In contrary to "expectations," locum physicians provided shorter hospital stay, lower HC with the same readmission, and mortality compared to employed hospitalists. In patients treated variably by locum and/or employed hospitalists, our analysis showed that patients treated incrementally by locums relative to employed hospitalists had a shorter hospital stay and lower cost.

Because locum physicians provide shorter stay and lower $\mathrm{HC}$, it might be inaccurate to label locum physician care as "expensive." Studies are needed to unravel the net economic outcome of locum physician utilization.

Supplementary Information The online version contains supplementary material available at https://doi.org/10.1007/s11606-02006578-4.

Acknowledgments: Authors would like to thank Mr. John-Claude Acampa and Promedica's financial department for their help in providing hospital costs for hospitalized patients and their guidance in study design. Corresponding author: Moaath K. Mustafa Ali, MD, MPH. Department of Medicine, University of Toledo/Promedica Toledo Hospital and Bloomberg School of Public Health Johns Hopkins University. 2142 N. cove Blvd, Toledo, OH 43606 (moaath_mustafa@yahoo.com).

Corresponding Author: Moaath K. Mustafa Ali, MD, MPH; Department of Medicine, University of Toledo/Promedica Toledo Hospital, Toledo, OH, USA (e-mail: moaath_mustafa@yahoo.com).

Authors' Contributions Contributors: Dr. Mustafa Ali had full access to all the data in the study and takes responsibility for the integrity of data and the accuracy of the data analysis.

Concept and design: Mustafa Ali and McGready.

Acquisition, data analysis, and result interpretation: All authors.

Drafting of the manuscript: All authors.

Critical revision of the manuscript: All authors.

Statistical analysis: Mustafa Ali and McGready.

Administrative and technical support: Mustafa Ali.

Supervision: Mustafa Ali.

Compliance with Ethical Standards:

Conflict of Interest: All authors have no conflict of interests.

\section{REFERENCES}

1. Wachter RM, Goldman L. Zero to 50,000 - The 20th Anniversary of the Hospitalist. N Engl J Med 2016;375(11):1009-11. https://doi.org/10. 1056/NEJMp1607958.

2. Simmer TL, Nerenz DR, Rutt WM, Newcomb CS, Benfer DW. A randomized, controlled trial of an attending staff service in general internal medicine. Med Care. 1991;29(7 Suppl):Js31-40.

3. Shine D, Beg S, Jaeger J, Pencak D, Panush R. Association of resident coverage with cost, length of stay, and profitability at a community hospital. J Gen Intern Med 2001;16(1):1-8. https://doi.org/10.1111/j. 1525-1497.2001.00314.x.

4. Au AG, Padwal RS, Majumdar SR, McAlister FA. Patient outcomes in teaching versus nonteaching general internal medicine services: a systematic review and meta-analysis. Acad Med 2014;89(3):517-23. https://doi.org/10.1097/acm.0000000000000154.

5. Chin DL, Wilson MH, Bang H, Romano PS. Comparing patient outcomes of academician-preceptors, hospitalist-preceptors, and hospitalists on internal medicine services in an academic medical center. J Gen Intern Med 2014;29(12):1672-8. https://doi.org/10.1007/s11606-014-2982-y.

6. Perez JA, Jr., Awar M, Nezamabadi A, Ogunti R, Puppala M, Colton L, et al. Comparison of Direct Patient Care Costs and Quality Outcomes of the Teaching and Nonteaching Hospitalist Services at a Large Academic Medical Center. Acad Med 2018;93(3):491-7. https://doi.org/10.1097/ acm.0000000000002026.

7. Abusaada K, Alsaleh L, Herrera V, Du Y, Baig H, Everett G. Comparison of hospital outcomes and resource use in acute COPD exacerbation patients managed by teaching versus nonteaching services in a community hospital. J Eval Clin Pract 2017;23(3):625-30. https:// doi.org/10.1111/jep. 12688 .

8. Everett G, Uddin N, Rudloff B. Comparison of hospital costs and length of stay for community internists, hospitalists, and academicians. J Gen Intern Med 2007;22(5):662-7. https://doi.org/10.1007/s11606-007-0148-x.

9. Adams JG, Walls RM. Supporting the Health Care Workforce During the COVID-19 Global Epidemic. Jama. 2020. https://doi.org/10.1001/ jama.2020.3972. 
10. Nolan TL, Kandel JJ, Nakayama DK. Quality and extent of locum tenens coverage in pediatric surgical practices. Am Surg 2015;81(4):37780 .

11. Inoue $\mathbf{K}$, Matsumoto $\mathbf{M}$, Igarashi $\mathbf{M}$. Short term locum tenens for rural practice: a trial of a Japanese medical school. Australian J Rural Health 2002;10(2):80-6.

12. Salloch S, Apitzsch B, Wilkesmann M, Ruiner C. Locum physicians professional ethos: a qualitative interview study from Germany. BMC Health Serv Res 2018;18(1):333. https://doi.org/10.1186/s12913-0183118-6.

13. Doan BD, Levy D, Pavot J. Demographic forecasts of medical workforce supply in France (2000-2050). What numerus clausus for what future? Cahiers Sociol Demogr Med 2004;44(1):101-48.

14. McKevitt C, Morgan M, Hudson M. Locum doctors in general practice: motivation and experiences. Br J Gen Pract 1999;49(444):519-21.

15. Simon AB, Alonzo AA. The demography, career pattern, and motivation of locum tenens physicians in the United States. J Healthe Manag. 2004;49(6):363-75; discussion 75-6.

16. STAFF CARE. 2020 Survey of temporary physician staffing trends. 2020. https://www.staffcare.com/uploadedFiles/staffcare2020surveyPDF.pdf. Accessed 4/24/2020.

17. Locum Story. Locum tenens physicians and COVID-19: Where we stand. 2020. https://locumstory.com/spotlight/locum-tenens-covid-19/. Accessed 6/26/2020

18. Grabl L. Locum tenens are crucial during a time of crisis. 2020. https:// www.physicianspractice.com/view/locum-tenens-are-crucial-duringtime-crisis. Accessed 6/26/2020.

19. Ferguson $\mathbf{J}$, Walshe $\mathbf{K}$. The quality and safety of locum doctors: a narrative review. J R Soc Med 2019;112(11):462-71. https://doi.org/10. 1177/0141076819877539.

20. Thy M, Bardon J, Carbonne $\mathbf{H}$. Evaluation of locum tenens activity by young anaesthesiologists and intensivists: A national survey. Anaesthesia Critic Care Pain Med 2019;38(1):85-6. https://doi.org/10.1016/j.accpm. 2018.04.005.

21. Blumenthal DM, Olenski AR, Tsugawa Y, Jena AB. Association Between Treatment by Locum Tenens Internal Medicine Physicians and 30-Day Mortality Among Hospitalized Medicare Beneficiaries. Jama. 2017;318(21):2119-29. https://doi.org/10.1001/jama.2017.17925.
22. Office for Human Research Protections. 45 Code of Federal Regulations 46. 2018. https://www.ecfr.gov/cgi-bin/retrieveECFR?

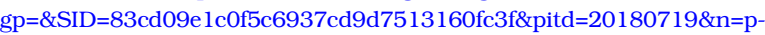
t45.1.46\&r=PART\&ty=HTML. Accessed 11/13/2019.

23. Kontopantelis E, Doran T, Springate DA, Buchan I, Reeves D. Regression based quasi-experimental approach when randomisation is not an option: interrupted time series analysis. BMJ 2015;350:h2750. https://doi.org/10.1136/bmj.h2750.

24. Ohio Department of Health. Active hospitals in Lucas county. Ohio Department of Health. http://publicapps.odh.ohio.gov/eid/Search_Results.aspx. Accessed 11/26/2019.

25. R Development Core Team R. R: A language and environment for statistical computing. $\mathrm{R}$ foundation for statistical computing Vienna, Austria; 2019.

26. Young JQ, Ranji SR, Wachter RM, Lee CM, Niehaus B, Auerbach AD. "July effect": impact of the academic year-end changeover on patient outcomes: a systematic review. Ann Intern Med 2011;155(5):309-15. https://doi.org/10.7326/0003-4819-155-5-201109060-00354.

27. Rich EC, Hillson SD, Dowd B, Morris N. Specialty differences in the 'July Phenomenon' for Twin Cities teaching hospitals. Med Care 1993;31(1):73-83. https://doi.org/10.1097/00005650-19930100000006.

28. Barry WA, Rosenthal GE. Is there a July phenomenon? The effect of July admission on intensive care mortality and length of stay in teaching hospitals. J Gen Intern Med 2003;18(8):639-45. https://doi.org/10. 1046/j.1525-1497.2003.20605.x.

29. Averbukh Y, Southern W. A "reverse july effect": association between timing of admission, medical team workload, and 30-day readmission rate. J Grad Med Educ 2014;6(1):65-70. https://doi.org/10.4300/ JGME-D-13-00014.1.

30. Stuart EA. Matching methods for causal inference: A review and a look forward. Stat Sci 2010;25(1):1-21. https://doi.org/10.1214/09-STS313.

Publisher's Note Springer Nature remains neutral with regard to jurisdictional claims in published maps and institutional affiliations. 